\title{
PURPOSEFUL EXPLANATION AND CAUSAL GAPS
}

\section{STEWART GOETZ}

Urisnus College

\begin{abstract}
In this paper, I argue that a commitment to science and the methodological commitment to causal closure do not require a rejection of the idea that the choices of souls explain the occurrence of certain events in the physical world. Stated slightly differently, I maintain that one can both affirm science and believe that souls causally interfere in the course of events in the physical world. Such an affirmation and belief are compatible. In short, science vis-à-vis the methodological principle of causal closure poses no problem for souls as explanatory agents.
\end{abstract}

I.

The majority opinion among analytic philosophers is that there is no explanatory room in the physical world for a soul (assuming that it exists) that chooses for purposes. This is because of the methodological principle of the causal closure of the physical world and the role this principle occupies in science. Given that science requires a commitment to the causal closure of the physical world, it also requires a commitment to the exclusion of souls as explanatorily relevant. In short, if souls exist, they cannot and do not do any explanatory work.

In this paper, I argue that a commitment to science and the methodological commitment to causal closure do not require a rejection of the idea that the choices of souls explain the occurrence of certain events in the physical world. Stated slightly differently, I maintain that one can both affirm science and believe that souls butt into the course of events in the physical world. Such an affirmation and belief are compatible. In short, science vis-à-vis the methodological principle of causal closure poses no problem for souls as explanatory agents. 
II.

The experimental cognitive scientist Jesse Bering has recently argued that human beings are believers in soul- or mind-body substance dualism. ${ }^{1}$ As Bering sees things, Darwinian natural selection produced a cognitive system that gave rise to this dualistic folk psychology about souls. Similarly, the psychologist Nicholas Humphrey, in his book Soul Dust, recognizes the human inclination to believe in substance dualism. ${ }^{2}$ Toward the end of his book, Humphrey points out that other scholars also acknowledge this ordinary belief in substance dualism:

Thus, developmental psychologist Paul Bloom aptly describes human beings as 'natural-born dualists'. Anthropologist Alfred Gell writes: 'It seems that ordinary human beings are "natural dualists", inclined more or less from day one, to believe in some kind of "ghost in the machine" ... Neuropsychologist Paul Broks writes: 'The separateness of body and mind is a primordial intuition. ... Human beings are natural born soul makers, adept at extracting unobservable minds from the behaviour of observable bodies, including their own.'

Though Bering, Humphrey, Bloom, Gell, and Broks maintain that human beings naturally believe in substance dualism, all of these authors also insist that this belief in substance dualism is false and rests on an illusion. Among academics, the denial of substance dualism is standard fare. What is also standard fare is adherence to a metaphysical thesis known as 'naturalism', which for my purposes I will assume is the position that the final and complete account of all that happens in the physical world must and will exclude (eliminate) irreducible purposeful/ teleological explanation. Thus, naturalists affirm that if there is any viable form of mental-to-physical explanation (that is, a mental explanation of a physical event), it will be causal, and no more than causal, in nature. Given their naturalism, these naturalists affirm the ontological principle of the causal closure of the physical world, which for the purposes of this paper I will understand as the thesis that every physical event that is an effect has a complete physical event-cause, where a physical eventcause is a complete explanation of a physical effect event in the sense

${ }^{1}$ Jesse Bering, 'The Folk Psychology of Souls', Behavioral and Brain Sciences, 29 (2006): 453-498.

${ }^{2}$ Nicholas Humphrey, Soul Dust: The Magic of Consciousness (Princeton: Princeton University Press, 2011).

${ }^{3}$ Ibid., p. 195. 
that, given the former and the relevant laws of nature, there is nothing left to be explained about the occurrence of the latter. A commitment to ontological causal closure gives rise to a problem of mental-to-physical causation, the solution to which (if we exclude eliminativism and epiphenomenalism as viable options) seems to require that whatever is mental in nature be identical with what is physical in nature.

Now, if one has any robust soul-body convictions, where mental events are events in souls, then one will not find this naturalist 'solution' to the problem of mental-to-physical causation very attractive. Moreover, if one has any robust convictions about the freedom of the will that are libertarian in nature (I will understand libertarian free will as the freedom to make uncaused choices for purposes), one will have further reason to be sceptical about the naturalist's solution to the problem of mental-to-physical causation. ${ }^{4}$ This is because if one believes that a choice is uncaused (here I set aside consideration of agent causation, though the prospects for libertarian free will are not any better with agent causation, given naturalism's commitment to causal closure and the view that every physical effect event has a complete explanation in the form of a physical event-cause), then identifying a choice with a physical event that itself has a complete physical cause entails the end of one's libertarianism.

Finally, if one believes in the reality of irreducible purposeful explanation (that which is not reducible to causal explanation), one will have yet another reason not to accept the naturalist's resolution of the problem of mental-to-physical causation. And if a purposeful explanation of a mental event leaves nothing to be explained about the occurrence of that mental event (in this sense, it is a complete explanation of this event), so that any other explanation of that event would be superfluous, then it is not unreasonable to conclude that there is no causal explanation of that event. But if there is no causal explanation of that mental event, then it cannot be identical with a physical event that has a physical eventcausal explanation. Therefore, the naturalist's solution to the problem of mental-to-physical causation will prove unacceptable to the person who believes in irreducible and ineliminable purposeful explanations.

The ontological principle of causal closure has occupied a prominent place in various naturalists' attempts to defend naturalism. However, as E. J. Lowe points out, it is not easy to state a form of the ontological

${ }^{4}$ E. J. Lowe, Personal Agency: The Metaphysics of Mind and Action (Oxford: Oxford University Press, 2008), pp. 67-68. 
causal closure principle that is not basically a dogma that begs the question against someone who believes in irreducible and ineliminable mental-to-physical causation. ${ }^{5}$ Regardless of whether or not it is such a dogma, I'm going to set it aside and turn to a sister principle of causal closure that is methodological in nature and equally, if not more, popular with naturalists. What naturalists have in mind with this methodological principle of the causal closure of the physical world is something like the following: if there is anything about which we can be confident in the modern world, it is that science is the final court of appeal in all matters philosophical. Thus, anything that conflicts with the deliverances of science (e.g., substance dualism and libertarian free will) is unacceptable. But science has developed its authority by making use of certain assumptions, one of which is the methodological principle of causal closure. A comment by the naturalist Humphrey, whom I quoted earlier as recognizing the human inclination to believe substance dualism, helps to illustrate this point. He asserts that when it comes to explaining human behaviour, the scientific study of the brain will reveal all that there is to know. And his reason for saying this? 'My reason is simply the guiding principle, which underlies all science, that nothing

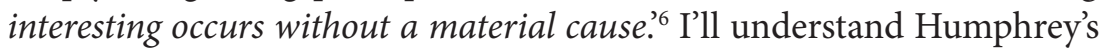
claim as a way of saying that science has a methodological commitment to exclude any mental explanation, involving a substantial soul or mind, of the occurrence of a physical event. Jaegwon Kim captures this point about methodological causal closure with the following example:

You want to raise your arm, and your arm goes up. Presumably, nerve impulses reaching appropriate muscles in your arm made those muscles contract, and that's how the arm went up. And these nerve signals presumably originated in the activation of certain neurons in your brain. What caused those neurons to fire? We now have a quite detailed understanding of the process that leads to the firing of a neuron, in terms of complex electrochemical processes involving ions in the fluid inside and outside a neuron, differences in voltage across cell membranes, and so forth. All in all we seem to have a pretty good picture of the processes at this microlevel on the basis of the known laws of physics, chemistry, and biology. If the immaterial mind is going to cause a neuron to emit a signal (or prevent it from doing so), then it must somehow intervene in

\footnotetext{
${ }^{5}$ Ibid., pp. 42, 63.

${ }^{6}$ Humphrey, Soul Dust, p. 17. The emphasis is Humphrey's.
} 
these electrochemical processes. But how could that happen? At the very interface between the mental and the physical where direct and unmediated mind-body interaction takes place, the nonphysical mind must somehow influence the state of some molecules, perhaps by electrically charging them or nudging them this way or that way. Is this really conceivable? Surely the working neuroscientist does not believe that to have a complete understanding of these complex processes she needs to include in her account the workings of immaterial souls and how they influence the molecular processes involved. ... Even if the idea of a soul's influencing the motion of a molecule ... were coherent, the postulation of such a causal agent would seem neither necessary nor helpful in understanding why and how our limbs move. ... Most physicalists ... accept the causal closure of the physical not only as a fundamental metaphysical doctrine but as an indispensable methodological presupposition of the physical sciences. ... If the causal closure of the physical domain is to be respected, it seems prima facie that mental causation must be ruled out ...

Kim says that the working neuroscientist does not need to make reference to the idea of a soul causally influencing molecular processes to have a complete understanding of what goes on physically when you raise your arm. I will examine this claim of his in a moment. Before doing so, I think it is helpful to ask why it is plausible to maintain that the causal closure of the physical world is an indispensable methodological presupposition of the physical sciences. Alvin Plantinga has asked this question in his examination of what he calls methodological naturalism, which is, for the purposes of my paper, equivalent to the methodological principle of causal closure. ${ }^{8}$ Plantinga points out that our conception of science has been bequeathed to us by the Enlightenment, which itself sought to teach us to demarcate clearly between faith (which is private and subjective) and reason (which is public and objective). Science is that which supposedly embodies reason, most especially in the form of verifiable and shareable facts that are equally available to anyone, whatever a person's metaphysical convictions. But Plantinga recognizes that pointing out the genealogical line of modern science does little to help us understand why a scientist must, in order to do science, be bound by the methodological principle of the causal closure of the physical

\footnotetext{
7 Jaegwon Kim, Philosophy of Mind (Boulder, CO: Westview, 1996), pp. 131-132; 147-148.

${ }^{8}$ Alvin Plantinga, 'Methodological Naturalism?', Perspectives on Science and Christian Faith, 49 (1997), 143-154.
} 
world. In his effort to find an answer to this question, Plantinga goes on to quote the suggestion of the naturalist Michael Ruse that a scientist's commitment to the methodological principle of the causal closure of the physical world is tied to the idea that science deals with what is natural, repeatable, and governed by law. But, says Plantinga, Ruse's suggestion cannot be right because presumably the Big Bang is something with which science is concerned, yet it is unique and unrepeatable. Moreover, says Plantinga, the idea of a causal law has its own chequered history, with philosophers of science like Bas van Fraassen maintaining that there are no natural laws. Plantinga points out that there are no doubt regularities among events in the physical world, but regularities are not necessarily laws, and trying to explain the difference between nomic and nonnomic regularities has proven to be messy business.

After some further discussion, Plantinga gets around to considering what he calls Duhemian science (named after the Roman Catholic scientist Pierre Duhem), which is the idea that science should not be dependent upon metaphysical commitments. Because metaphysical commitments are plentiful in number and tenaciously held, Duhem believes that if science were dependent upon them, disagreements would run riot. Duhem's point, according to Plantinga, is that all who embrace science need to embrace the methodological principle of causal closure so that riots are avoided and science can be a cooperative venture.

Duhemian science, then, seeks to be maximally inclusive, and Plantinga seems willing to concede the workability of a Duhemian view of science when it comes to the hard sciences like physics, chemistry, biology, and neuroscience (he is not so sanguine about the Duhemian view for a human science like psychology, but given an inclusion of purposeful explanations in psychology, it is not clear that psychology is a science). Plantinga, however, is not done with his investigative work about the basis for accepting the methodological principle of the causal closure of the physical world, and he raises one last issue that he seems to think gets at the heart of the matter. This final issue is the idea of something's being, in his words, a 'science stopper'. Speaking as a theist, Plantinga writes:

One of the things we want to do as [God's] creatures is to understand the world he has made, see (to the extent that we can) how it is made, what its structure is, and how it works.... This is what goes on in natural science. The object of this science is nature ... But there will be little advance along 
this front if, in answer to the question, Why does so and so work the way it does? or What is the explanation of so and so? we regularly and often reply 'Because God did it that way' ... Ascribing something to the direct action of God tends to cut off further inquiry.

The point Plantinga is making on behalf of the methodological principle of causal closure can plausibly be expanded into something like the following: One reason for requiring a commitment to the methodological principle of causal closure is the notion of scientific progress. After all, if science were at some point to reach a dead end in the attempt to discover a physical cause of a physical effect and did not in principle assume causal closure, then after some time of frustration it would be tempting to step outside the physical order and appeal to a non-physical, mental explanation (Plantinga thinks of such an explanation in the form of God; I, along with Kim, Humphrey, and the others I have quoted, am thinking of it in terms of the soul). But that would for all intents and purposes undercut any further reason for continuing to search for a physical cause. One can only imagine how many fewer scientific discoveries would have been made had the methodological principle of the causal closure of the physical world been rejected.

III.

Plantinga's response to the above justification for methodologically assuming in principle that the physical world is causally closed is to say that the fact that appeals to God are science stoppers means that, as a general rule, they will not be helpful. However, it does not mean that they are never true. ${ }^{10}$ But if such appeals are science stoppers and also sometimes true, how are we to sort out when it is, and when it is not, reasonable to believe that there must be a stop to science and an appeal made to God? And what about the methodological principle of the causal closure of the physical world? The answers to these questions are by no means easy to come by. But I think we can make some, even if it is a little, headway in answering them by initially thinking of what is excluded as an explanation of a physical event by the methodological principle of causal closure in terms of a human soul, instead of God. This is the case, for three reasons.

\footnotetext{
${ }^{9}$ Ibid., p. 152.

${ }^{10} \mathrm{Ibid}$.
} 
First, as Humphrey writes, 'Long before religion could begin to get a foothold in human culture, human beings must already have been living in soul land.... Religion is parasitic on spirituality (and not, as some religionists would have it [and here one is tempted to think of Plantinga], the other way round.' ${ }^{11}$ Second, it is not implausible to think of God as akin to a divine soul, and if the problem of methodological causal closure cannot be met vis-à-vis the human soul, there is good reason it cannot be met with respect to God. And third, because Kim has nicely posed the problem of methodological causal closure in terms of the soul, we have at hand a clear formulation of the problem with which to work.

So, what might be said in response to the argument against substance dualism and for naturalism that puts front and centre the methodological principle of the causal closure of the physical world? Well, there is no need for the advocate of this methodological principle to assume that there are no souls. That would unnecessarily invoke metaphysics in a way that Duhem believes would poison the scientific enterprise. So, let us have the naturalist advocate of the methodological principle of causal closure concede, for the sake of argument, at least the existence of immaterial minds or souls. What this naturalist advocate is intent on maintaining is that even if souls exist, the pursuit of science requires the principled assumption that the world is causally closed to intervention by them. This is the thrust of Kim's point. This concessionary but equally principled position seems to be advocated by the geneticist and evolutionary biologist J. B. S. Haldane. He says: 'My practice as a scientist is atheistic. That is to say, when I set up an experiment I assume that no god, angel or devil is going to interfere with its course ... I should therefore be intellectually dishonest if I were not also atheistic in the affairs of the world. ${ }^{12}$ With a little argumentative license, it is fair to understand Haldane as claiming not only that his practice as a scientist is atheistic insofar as he methodologically assumes the physical world is causally closed to divine intervention but also that it is more broadly physicalistic insofar as it includes the assumption that no human soul is going to interfere with the course of the physical world that he is studying. Likewise, it is fair to assume that Haldane believes he would be intellectually dishonest were he not also a physicalist with

${ }^{11}$ Humphrey, Soul Dust, p. 205.

12 J. B. S. Haldane, Fact and Faith (London: London, Watts \& Co., 1934); quoted in L. M. Krauss, 'God and Science Don't Mix', The Wall Street Journal, June 26, 2009. 
regard to the living of his life outside the science lab (what he calls 'the affairs of the world').

The question I want to consider now is whether it follows from the fact that a scientist must methodologically assume the causal closure of the physical world with respect to souls when he is doing his science that he must also methodologically assume, lest he be intellectually dishonest, the causal closure of the physical world with respect to souls when he pursues the affairs of everyday life. By the end of this paper, I hope to make clear that there is neither intellectual dishonesty nor inconsistency in affirming methodological causal closure of the physical world in the science lab while denying it outside that context in the affairs of everyday life.

To begin constructing a response to Haldane, I need briefly to sketch a picture of how we ordinarily view ourselves in daily life and an implication of this view for our relationship to our physical bodies as we conduct the everyday affairs of life. My sketch begins with the idea that people are or have souls and on occasion make undetermined choices (from here on, I will assume that choices are essentially undetermined events), where this implies that those souls, via their choices, causally influence the courses of events in their physical bodies. The making of choices on these occasions implies that people at that time have reasons for performing incompatible actions. It is because they cannot perform both actions that they must make a choice to do one or the other (or neither), and whichever choice they make, they make that choice for a reason or purpose, where that reason provides an ultimate and irreducible teleological explanation of that choice. The making of a choice is a mental event that occurs in a soul and either it, or some other mental event associated with it (e.g., an intention to act) must directly causally produce an effect event in that soul's physical body. So our view of ourselves as engaging in the affairs of ordinary life implies that there is mental-to-physical causation and its occurrence is ultimately and irreducibly explained teleologically by the reason that explains the making of a choice.

To put some flesh on the proverbial bones, consider the movements of my fingers right now on the keys of my keyboard as I work on this paper. If these movements occur because of a choice of mine to type, then these physical movements are ultimately and irreducibly explained teleologically in terms of the purpose for making my choice to write this paper, which, we can suppose, is that I make clear that there is no good objection from the methodological assumption of the causal closure 
of the physical world to the view that human beings are soul-body compounds and that those souls make choices that causally produce (directly or indirectly) effect events in their physical bodies. Hence, if the movements of my fingers are ultimately occurring because I made a choice to write this essay for a purpose, then a mental event involving me (a soul) must be causing those movements to occur as I write this essay for the just-stated purpose. In other words, if our commonsense view of a human being is correct, $\mathrm{I}$, as a soul, cause events to occur in the physical world by making a choice to write this essay for a purpose.

Two intermediate points are appropriate here. First, from the example of my typing, it is important to make clear that the claim that there is causal interaction between a soul and its physical body is not a 'God-ofthe-gaps' type of argument. In discussions about God's existence, critics often argue that theists postulate God's existence in light of an inability of science to provide a complete explanation for a physical datum (or data). This lack of a complete explanation is a gap in the scientific story. By analogy, a critic might argue that I am postulating my soul's existence in light of an inability of science to provide a complete explanation for the movements of my fingers when I type this essay. But this argument would be mistaken. My claim is not that there are certain physical events (the movements of my fingers) for which a failure to find a complete physical causal story warrants appeal to the causal activity of a soul as their ultimate explanation. Rather, the claim is that our commonsense understanding of our purposeful activity entails that some physical events must occur whose ultimate causal explanation is not other physical events but non-physical mental events whose occurrences are explained teleologically by purposes.

Second, the choice made for a purpose that directly or indirectly causally produces a physical effect event is, in Plantinga's terms, a science stopper. On an occasion when such a choice is made, there will have to be an initial physical event for which there is no sufficient physical cause. And we know that this must be the case, given that we make choices for purposes. And when I say that 'we' know this must be the case, I am assuming that scientists, too, know this. What then about the matter of intellectual dishonesty and inconsistency on the part of a scientist. What can be said in response to Haldane?

Consider once again Kim's neuroscientist, and let us distinguish between a neuroscientist as an ordinary human being and a neuroscientist as a physical scientist. Surely a neuroscientist as an ordinary human 
being who is trying to understand how and why my fingers move while I am typing must and would refer to me and my reasons (purposes) for acting in a complete account of why my fingers move. Must she, however, as a physical scientist, avoid making such a reference? Kim claims that she must avoid such a reference because as a physical scientist she must make a methodological assumption about the causal closure of the physical world. Is Kim right about this and, if he is, is such a commitment compatible with a commitment on the part of a physical scientist as an ordinary human being to the causal openness of the physical world? Or must a neuroscientist, who as a physical scientist assumes methodological causal closure, also assume, if she is not to be dishonest and/or inconsistent, that as an ordinary human being her mention of purposeful explanations of choices is, say, nothing more than an explanatory heuristic device that is necessary because of an epistemic gap in her knowledge concerning the physical causes of human behaviour?

In order to answer these questions, it is necessary to consider what it is about physical entities that a physical scientist such as a neuroscientist is often trying to discover in her experimental work. What is, dare we ask, the purpose of a neuroscientist's inquiry? In the case of Kim's neuroscientist, it is eminently plausible to think, as one of Plantinga's earlier comments suggests, that what she is trying to discover as a physical scientist is how the physical world works, and this involves learning about the capacities of particles or micro-physical entities such as neurons and how they are causally affected by exercised causal powers of other physical entities, including other neurons.

Here, it is helpful to consider the pioneering work on the brain of Wilder Penfield, as he describes it in his book The Mystery of the Mind. ${ }^{13}$ Penfield recounts how he produced movements in the limbs of patients by stimulating the cortical motor areas of their brains with an electrode. As Penfield observed the neural impulses that resulted from stimulation by the electrode, he did what Haldane advocates and methodologically assumed during his experiments that the areas of the brains of his patients on whom he was doing his scientific work were causally closed to other causal influences. Without this methodological assumption of causal closure, he could not conclude both that it was the electrode, as opposed,

${ }^{13}$ Wilder Penfield, The Mystery of the Mind (Princeton: Princeton University Press), 1975. 
say, to something 'behind the scene' such as an empirically undetectable human soul, that causally affected the capacities of the neurons to conduct electrical impulses, and that it was the causal impulses of those neurons that causally affected the same capacities of other neurons further down the causal chains to produce the movements of the limbs. There is no reason, however, to think, contrary to what Haldane maintains, that because Penfield's investigation of the brain required the methodological assumption of causal closure of the areas of the brains he was studying during his experiments that he also had to be committed as a physical scientist to the assumption that the physical world is universally (in every context) causally closed, where universal causal closure entails that the relevant brain (neural) events can only be causally produced by events of other physical entities and not instead by mental events of immaterial souls alone when they indeterministically choose and intend (plan) to act for purposes. That is, there is no reason to think that because a neuroscientist like Penfield must assume causal closure of a delimited area of the brain in the context of his experimental work in order to discover how physical entities causally interact with each other that he must also be committed as a scientist to the universal explanatory exclusion of mental events of souls that on certain occasions cause the occurrence of events in the physical world. All that the neuroscientist as a physical scientist must assume is that during his experiments souls (either the patients themselves or others) are not directly causally producing the relevant events in the micro-physical entities in the areas of the brain that he is studying. If the neuroscientist makes the universal assumption that in any context events in micro-physical entities can only have other physical events as causes and can never be causally explained by mental events of souls and their purposes, then he does so not as a scientist but as a naturalist, where, as I indicated at the outset of this paper, a naturalist is a person who believes that the occurrence of physical events can only be explained in terms of the occurrence of other physical events and without any reference to ultimate and irreducible purposes.

It is relevant to note in this context that Penfield himself was not a naturalist. Rather, he was a soul-body dualist. ${ }^{14}$ One can surmise, then, that were Penfield to have been presented by Kim or Haldane with the methodological argument from causal closure, he would have found it wanting. And for good reason. In seeking to understand how events

${ }^{14}$ Ibid., pp. 76, 80. 
of different physical entities affect the capacities of micro-entities such as neurons, a neuroscientist such as Penfield is seeking to learn about properties of physical entities that are essentially conditional or iffy in nature. A property that is conditional in nature is a property that is specified in terms such as 'If such-and-such is done to object $\mathrm{O}$ (e.g., a cause $\mathrm{C}$ is exerted on $\mathrm{O}$ ), then so-and-so will occur to $\mathrm{O}$ (e.g., $\mathrm{O}$ will move at rate R)'. As the Nobel physicist Richard Feynman says, scientific questions are 'questions that you can put this way: "if I do this, what will happen?" ... And so the question "If I do it what will happen?" is a typically scientific question. ${ }^{15}$ The following description by David Chalmers of the basic particles that are studied by physicists nicely captures their iffy nature:

Basic particles ... are largely characterized in terms of their propensity to interact with other particles. Their mass and charge is specified, to be sure, but all that a specification of mass ultimately comes to is a propensity to be accelerated in certain ways [moved at certain rates] by forces, and so on. ... Reference to the proton is fixed as the thing that causes interactions of a certain kind that combines in certain ways with other entities, and so on ... ${ }^{16}$

What Chalmers describes as a 'propensity' of a particle to be accelerated is a capacity of it to be moved which is such that if it is actualized (triggered) by an exercised causal power of another entity (whether physical or non-physical in nature), the particle will be necessitated to behave in a certain way. There is nothing, however, in the nature of the propensity or capacity of that particle that entails that it can only be actualized by the exercised power of a physical entity. That is, there is nothing in the nature of that propensity or capacity that entails that it cannot be actualized by souls making undetermined choices for reasons. (If there were something about the ontological nature of a capacity of a physical object that it could only be actualized by physical causal events, then Haldane would not need to assume that no god, angel or devil is going to interfere with the course of his experiment. Such an assumption would be superfluous.) Hence, the actualization of a microparticle's capacity to behave in a certain way by a person on an occasion

${ }^{15}$ Richard Feynman, The Meaning of It All (Reading, MA: Perseus Books, 1998), pp. 16, 45 .

${ }^{16}$ David Chalmers, The Conscious Mind: In Search of a Fundamental Theory (New York: Oxford University Press, 1996), p. 153. 
when the latter makes a choice for a reason is not excluded by anything that is discovered in a scientific study of that capacity. And it is precisely on occasions like those noted by Kim, when finger and arm movements occur seemingly for purposes, that a neuroscientist will reasonably believe that the originative micro-physical movements are produced by the causal activity of a soul that is choosing to act for a purpose. If a neuroscientist makes the presupposition that micro-physical entities can have their capacities actualized only by other physical entities and never by choices made by souls for purposes, then he does so as a naturalist and not as a scientist.

My response to the causal closure argument assumes Feynman's and Chalmers' iffy picture of micro-entities that, in addition to being iffy, is also deterministic in the sense that no effect will occur in any microentity unless some causal event determines or necessitates that effect to take place. Might there not, however, be random (non-deterministic) changes in the system of micro-entities as well as the deterministic ones? In other words, while sometimes a neuron fires because it gets deterministic causal input from the neurons with which it is connected, at other times it fires at random (without any deterministic cause), perhaps as a result of random quantum fluctuations in a chaotic system that are magnified at the neuronal level.

If we assume for the sake of discussion that neurons do sometimes fire randomly, is it possible to distinguish sharply between those firings that occur randomly and those that occur as the result of being causally determined by a mental event of a soul? After all, the two kinds of firings are alike to the extent that neither has a physically deterministic cause. I believe that it is possible to make this sharp distinction between the two kinds of firings. The way to make the distinction is in terms of contexts that are known, in the case of ourselves, through first-person experience and, in the case of others, through third-person observation. All one need do is ask how plausible it is to maintain that every time a person purposefully chooses to do something such as move his fingers to type, an initial neuron just happens to fire at random (as a result of quantum fluctuations, etc.) with the result that finger movements occur that perfectly mesh with or map onto those that are intended by that person. Because such repeated coincidences would literally be, dare I say, miraculous, the only plausible view is that the neuron must not be firing randomly but because of the causal input from a soul choosing to act for a purpose. 
IV.

I conclude that a commitment to science and a belief in the soul's explanatory relevance on occasion to the course of events in the physical world are compatible. At least, the methodological principle of the causal closure of the physical world poses no problem for such a commitment and belief. And this is good news for those who think that a belief in the existence of the soul and its purposeful activity is not illusory. ${ }^{17}$

\section{BIBLIOGRAPHY}

Bering, Jesse M., 'The Folk Psychology of Souls', Behavioral and Brain Sciences, 29 (2006), 453-498

Chalmers, David, The Conscious Mind: In Search of a Fundamental Theory (New York: Oxford University Press, 1996)

Feynman, Richard, The Meaning of It All (Reading, MA: Perseus Books, 1998)

Humphrey, Nicholas, Soul Dust: The Magic of Consciousness (Princeton: Princeton University Press, 2011)

Kim, Jaegwon, Philosophy of Mind (Boulder, CO: Westview, 1996)

Krauss, L. M., 'God and Science Don't Mix', The Wall Street Journal, June 26, 2009

Lowe, E. J., Personal Agency: The Metaphysics of Mind and Action (Oxford: Oxford University Press, 2008)

Penfield, Wilder, The Mystery of the Mind (Princeton: Princeton University Press, 1975)

Plantinga, Alvin, 'Methodological Naturalism?', Perspectives on Science and Christian Faith, 49 (1997), 143-154

${ }^{17}$ Acknowledgment: This paper was originally presented in Munich, at a conference for the Analytic Theology Project, generously funded by the John Templeton Foundation. 